\title{
Dental anxiety and the effectiveness of local anesthesia
}

\author{
Hadi Esmaeili (iD, Mohammad Malekzadeh2,* iD, \\ Davood Esmaeili $^{1}$ iD, Farid Nikeghbal ${ }^{3}$ iD
}

${ }^{1}$ School of dentistry, Yasuj University of Medical Sciences, Iran

${ }^{2}$ Social Determinants of Health Research Center, Yasuj University of Medical Sciences, Iran. ( ${ }^{\star}$ Corresponding author)

${ }^{3}$ Department of Operative Dentistry, School of Dentistry, Yasuj University of Medical Sciences, Iran.
*Corresponding author: Mohammad Malekzadeh Social Determinants of Health research center, Yasuj University of Medical Sciences, Iran

Email:mzh541@yahoo.com Mobile number: 00989171454340

Received: January 18, 2020

Accepted: July 12, 2020
Aim: The successful anesthesia is an essential factor for dental treatment. This study aimed at determining the effectiveness of local anesthesia and it's relationship with dental Anxiety. Methods: This cross-sectional study was carried out on 256 dental patients, in Gachsaran, Iran in 2017. Dental Anesthesia was administered after completing the Modified Dental Anxiety Scale by the patients. The level of anesthesia was recorded in one of three states (successful, difficult, and failed). Collected data was analyzed using SPSS version 22 and tests of, Chi-square, independent t-test, analysis of variance, and logistic regression model. Results: About $60.5 \%$ subjects had moderate-severe dental anxiety. The mean of dental anxiety significantly was lower in the successful anesthesia group $(P<0.01)$. Patients with elementary education had a significantly higher level of dental anxiety $(\mathrm{P}<0.01)$. Dental anxiety was significantly higher in the age group of $\geq 59$ years, compared to the other age groups, except for $49-58$ years $(P<0.05)$. Subjects with a significantly higher level of dental anxiety more delayed their visits to the dentist. The logistic regression model showed that the dental anxiety (high anxiety) and literacy level (elementary) were the most important predictors of failed or difficult anesthesia. Conclusion: Informing patients about dental treatment procedures, regular and periodic visits to the dentist, using psychotherapeutic techniques to reduce dental anxiety before anesthesia, could play an important role in the success of anesthesia.

Keywords: Anesthesia, local Dental anxiety, Pain. 


\section{Introduction}

Dental anxiety is a patients' response to stress in a dental setting ${ }^{1}$. Medical procedures cause a feeling of fear, inability, as well as anxiety ${ }^{2}$. It can be provoked due to multiple factors, such as previous negative or traumatic experience, sensory triggers such as sights of needles and air-turbine drills, sounds of drilling and screaming, vicarious learning from anxious people, patients' personality characteristics and their coping strategies ${ }^{3-8}$.

Several studies have reported high dental anxiety levels in approximately $10-20 \%$ of participants ${ }^{9,10}$.

Pain perception during the administration of local anesthetics is an essential reason for anxiety, and it may be caused by tissue puncture, pressure and velocity of fluid injection, the temperature of the anesthetic, and operator's skills ${ }^{11}$.

This problem can affect various treatment stages and complicate the situation for patients and dentists ${ }^{12}$.

Pain seems to be multifactorial and is influenced by psychological factors such as catastrophizing and anxiety ${ }^{13,14}$. People with a high score on pain catastrophizing reported more severe pain and anxiety, and they consume more analgesic medication ${ }^{15-17}$.

Anxious patients experience more negative and irrational thoughts related to dental treatment. They usually consider the worst-case scenario in their treatment. Avoiding dental treatment due to dental anxiety is related to more missing and decayed teeth ${ }^{18}$.

Poor oral and dental health can lead to dental diseases, which reduces the patients' quality of life and creates a vicious cycle, where patient's anxiety level increases and their health level decreases ${ }^{19,20}$.

One of the most important factors in patient satisfaction is pain control techniques. Canakci has stated that Measuring pain is difficult because it has physical and psychological aspects. It is subjective and depends on the patient's perception ${ }^{21}$.

Local anesthesia has enabled the profession to make tremendous therapeutic advances. Patients experience severe pain in case of failed anesthesia, which prevents many dental treatments, including root canal surgery, periodontal surgery, and tooth extraction ${ }^{22}$. Although dental anesthesia is an essential aspect of treatment for patients, an injection can induce anxiety or fear and maybe a reason for patients to avoid dental treatment ${ }^{23}$. Patients with high levels of anxiety usually exhibit lower pain thresholds ${ }^{24}$, and therefore, there is a decreased anesthesia success rate among these patients, and complementary methods are required in this regard. Notably, dentists' efforts and motivation to prevent pain in patients play an essential role in keeping them calm and relax ${ }^{25}$.

Dental anxiety can affect a patient's life. Physiological effects include signs and symptoms of fear and fatigue appears after a dentist's appointment, whereas cognitive impacts are a set of negative beliefs and thoughts. Behavioral results show itself as eating, lack of oral hygiene, self-treatment, and aggression. Moreover, dental anxiety can have adverse effects on general health due to its association with sleeping disor- 
ders. Furthermore, the social interactions and performance of these individuals at the workplace may decrease due to a lack of self-esteem and self-confidence ${ }^{26}$.

Medical evidence shows a strong relationship between oral and general health. Periodontal diseases and systemic diseases have a bidirectional relationship, and there are more than 100 systematic diseases with oral manifestations, such as cardiovascular diseases, stroke, respiratory infections (e.g., aspiration pneumonia), pancreas cancer, diabetes, and nutritional problems. Therefore, it can be stated that the treatment of oral diseases plays a vital role in the general health ${ }^{27,28}$. Given the importance of successful anesthesia for dental care treatments, recognition, and control of factors involved in its effectiveness can help increase the possibility of successful anesthesia.

This study differs from other studies in two ways. In most studies, patients 'anxiety levels were measured at the end of treatment. In contrast, in the present study, patients' anxiety was measured before starting treatment, indicating dental anxiety related to the patient's previous experiences.

Besides, most studies have measured patients' pain at the end of treatment with methods such as visual analog scale (VAS), while in this study, the success rate of anesthesia has been considered.

Given the fact that the majority of studies have assessed the relationship between anxiety and pain level, and little attention has been paid to the success of anesthesia, the present study aimed to determine the relationship between dental anxiety and the success rate of anesthesia in dental patients.

\section{Materials and Methods}

This cross-sectional study was conducted between February and December 2016.

after receiving permission from the research council and the ethics committee of Yasuj University of Medical Sciences. From 15 dental clinics in Gachsaran city in the south of Iran, five clinics were randomly selected by cluster sampling. Among the patients referred to these clinics, 256 patients who met inclusion criteria were randomly selected by simple random sampling.

The inclusion criteria for participation in the study were adults aged between 18 and 70 years, no cognitive impairment, and obtaining informed consent to participate in the study.

In this study, all patients approached by the same processes. At each dental clinic, patients were given the necessary explanations about the purpose of the research and how to fill out the questionnaires by a person with a bachelor's degree in psychology who had received the necessary training. Also, five dental surgeons with more than ten years of experience performed local anesthesia, who had already received the required training about the study, method of local anesthesia, and its success rate.

At first, research objectives were explained to the patients waiting for their dental treatment that required local anesthesia. In order to assess the anxiety level of patients before anesthesia, the modified dental anxiety scale (MDAS), demographic characteristics (age, gender, level of education, and the last dental visit) and informed 
consent form were completed by patients. After local anesthesia it's success rate was recorded by the dentist.

\section{Research Tools}

Modified dental anxiety scale (MDAS): The MDAS was applied to assess the anxiety of dental patients. This five-items questionnaire is scored based on a five-point Likert scale (from no anxiety $=1$ to extremely anxious=5). Besides, the score range of the scale is 5-25; a higher score indicates a higher anxiety level.

This total score can be classified, as follows:

Minimum anxiety (5-9), moderate anxiety (10-12), high anxiety (13-17), and extremely anxious (18-25) who need special care ${ }^{29}$.

In the present study, we applied $1.8 \mathrm{ml}$ 2\% lidocaine and 1:10000 epinephrine as local anesthesia. After 10 minutes of administration, the dentist evaluated the soft tissue (e.g., lips and gum) and hard tissue anesthesia in the mouth and related teeth using Pinprick and Cavity tests, respectively. In the Pinprick Test, a relatively sharp tool (e.g., a probe) is used to assess soft tissue anesthesia. In this context, the probe is entered into the desired tissue, and the level of pain perceived was compared to the soft tissues on the other side of the jaw. In case of soft tissue anesthesia, the cavity test was performed with a drill to determine whether hard tissue anesthesia was achieved or not.

In addition, the effect of dental anesthesia was recorded in one of the following three items:

1. Successful anesthesia: this item is selected if soft and hard tissue anesthesia is achieved in both tests, and the patient has no irregular pain during the treatment process.

2. Difficult anesthesia: anesthesia is re-administered by the dentist if the pain is perceived in a probe or drill test. In case of complete soft and hard tissue anesthesia after re-administration of anesthesia and the use of complementary injection techniques, this item is selected by the dentist.

3. Failed anesthesia: in case of lack of anesthesia in lips and mouth after re-administration of anesthesia and the use of complementary techniques, treatment is postponed to another day. In fact, the dentist announces anesthesia failure and selects this item.

\section{Data Analysis}

Data analysis was performed in SPSS version 22 using Chi-square, independent t-test, analysis of variance (ANOVA) tests and logistic regression model.

\section{Results}

From 256 subjects, 144 were female (56.3\%), and 112 were male (43.8\%). In addition, the mean age and standard deviation of the participants were $35.28 \pm 12.56$ years. Moreover, the mean and standard deviation of dental anxiety of the subjects was $14.08 \pm 6.56$. Furthermore, the mean and standard deviation of the last visit to the dentist was $33.06 \pm 35.87$ months. Other research variables are presented in Table 1 . 
Table 1. The number and percent of research variables

\begin{tabular}{|c|c|c|}
\hline variable & $\mathbf{N}$ & Percent \\
\hline \multicolumn{3}{|l|}{ age } \\
\hline $18-28$ & 74 & 28.9 \\
\hline $29-38$ & 75 & 29.3 \\
\hline $39-48$ & 30 & 11.7 \\
\hline $49-58$ & 9 & 3.5 \\
\hline 59 and higher & 17 & 6.6 \\
\hline \multicolumn{3}{|l|}{ gender } \\
\hline male & 112 & 43.8 \\
\hline female & 144 & 56.3 \\
\hline \multicolumn{3}{|l|}{ Education level } \\
\hline Elementary school & 73 & 28.5 \\
\hline High school & 106 & 41.4 \\
\hline university & 74 & 28.9 \\
\hline \multicolumn{3}{|l|}{ Local analgesia } \\
\hline failure & 11 & 4.3 \\
\hline difficult & 104 & 40.6 \\
\hline Successful & 140 & 54.7 \\
\hline \multicolumn{3}{|l|}{ Dental anxiety } \\
\hline No anxiety & 26 & 10.20 \\
\hline Low & 75 & 29.30 \\
\hline Moderate & 29 & 11.30 \\
\hline High & 32 & 12.50 \\
\hline Extreme & 94 & 36.70 \\
\hline
\end{tabular}

According to Table 1, most participants were in the age group of 29-38 years (29.3\%). In terms of literacy, most subjects were in the high school group (41.4\%). Furthermore, regarding dental anesthesia, the majority of participants were in the successful anesthesia group (57.4\%), followed by the group of difficult anesthesia group (40.6\%). In terms of dental anxiety, most subjects had mild anxiety (39.5\%), while $31.6 \%$ of the participants had very high dental anxiety. In general, $39.5 \%$ of the participants had mild anxiety, and $60.5 \%$ had anxiety ranging from moderate to extreme.

In this study, we applied the analysis of variance (ANOVA) to determine whether there was a difference among three groups of successful, difficult and failed anesthesia in the mean of anxiety (Table 2).

Table 2. ANOVA test to compare dental anxiety in three groups of successful, difficult and Failed anesthesia

\begin{tabular}{|c|c|c|c|c|c|}
\hline \multirow{2}{*}{ Local anesthesia } & \multirow{2}{*}{$\mathbf{N}$} & \multicolumn{2}{|c|}{ Anxiety } & \multirow{2}{*}{$F$} & \multirow{2}{*}{ sig } \\
\hline & & Mean & St.D & & \\
\hline failed & 11 & 17.9091 & 7.31375 & \multirow{3}{*}{29.95} & \multirow{3}{*}{0.001} \\
\hline difficult & 104 & 17.1923 & 6.44781 & & \\
\hline successful & 140 & 11.4857 & 5.40515 & & \\
\hline
\end{tabular}

St.D: standard deviation 
According to the mentioned table, there was a significant difference among the groups in the mean of anxiety $(P=0.001, F=29.95)$. Also, the Tukey Post Hoc Test was exploited to determine the substantial difference in groups regarding the mean of anxiety. In this regard, there was a significant difference between the group of successful anesthesia and the two groups of difficult anesthesia and failed anesthesia $(P<0.01)$. The results were indicative of a significantly lower dental anxiety in the subjects of the successful anesthesia group, compared to the other groups.

According to ANOVA results (Table 3), there was a significant difference between the three groups of elementary education, high school, and university degrees in the mean of dental anxiety $(P>0.01)$.

Table 3. ANOVA test to compare dental anxiety in three groups of elementary, high school and university level

\begin{tabular}{|c|c|c|c|c|c|}
\hline Educational level & $\mathrm{N}$ & Mean & St.D & $\mathrm{F}$ & sig \\
\hline elementary school & 73 & 17.08 & 6.45 & & \\
\hline High school & 106 & 12.77 & 6.33 & 11.22 & 0.001 \\
\hline university & 74 & 13.14 & 6.23 & & \\
\hline
\end{tabular}

St.D: standard deviation

According to Table 3, the mean dental anxiety was significantly different in three groups of elementary education, high school, and university degrees $(P<0.01)$.

The Tukey Post Hoc Test showed a significant difference between the group of elementary education with groups of high school and university degrees regarding mean dental anxiety $(P<0.01)$. The level of dental anxiety was higher in subjects with elementary education, compared to the other groups. However, no significant difference was found between the groups of high school and university degrees in this respect $(P>0.05)$.

Besides, ANOVA was indicative of a significant difference among various age groups regarding the mean anxiety level $(P<0.01)$. According to the results, there was a considerable difference between the age group of $\geq 59$ years and the age groups of 18-28 years $(P<0.05), 29-38$ years $(P<0.01)$, and 39-48 years $(P<0.01)$ in terms of dental anxiety. However, no significant difference was observed between the age groups of $\geq 59$ years and $49-58$ years $(P>0.05)$. The findings were also indicative of a higher dental anxiety level in the age group of $\geq 59$ years.

According to the Chi-square results, no significant relationship was observed between the level of anesthesia and variables of age and level of education $(P>0.05)$.

Table 4 shows the mean and standard deviation of the last visit (month) to the dentist at various anxiety levels. 
Table 4. The mean and standard deviation of the last visit to the dentist (month) at several levels of anxiety

\begin{tabular}{llll}
\hline \multirow{2}{*}{ Anxiety } & N & \multicolumn{2}{c}{ last visit } \\
\cline { 3 - 4 } & & Mean & St.D \\
\hline No anxiety & 17 & 12.02 & 12.28 \\
\hline low & 50 & 17.12 & 26.34 \\
\hline moderate & 20 & 14.91 & 11.75 \\
\hline high & 28 & 25.66 & 30.72 \\
\hline extremely & 91 & 52.01 & 39.20 \\
\hline
\end{tabular}

St.D: standard deviation

According to this table, the highest mean of last visits to the dentist $(52.01 \pm 39.20)$ was related to subjects with a high anxiety level. Also, ANOVA showed that the mean of the last visit to the dentist had a significant difference at various anxiety levels $(P=0.001, F=15.12)$.

According to the Tukey test, the group of high anxiety levels had a significant difference with other groups (no anxiety, low anxiety, moderate anxiety, and high anxiety) regarding the mean last visit to the dentist $(\mathrm{P}<0.01)$. In addition, the mean and standard deviation of the last visit to the dentist was significantly lower in female participants $(22.74 \pm 27.71)$ compared to male subjects $(45.12 \pm 40.44)(P<0.001)$.

Furthermore, we applied the logistic regression test to determine the most important predictors of the level of anesthesia. Level of anesthesia at two levels (successful anesthesia and difficult and failed anesthesia) was considered as the dependent variable while the variables of age, gender, literacy, and dental anxiety level were entered into the equation as independent variables. Finally, the variables of literacy level and anxiety were significant and remained in the regression equation. Since the $\mathrm{R}$ Square of the equation was equal to 0.39 , the independent variables (literacy level and dental anxiety level) predicted $39 \%$ of changes in the dependent variable (level of anesthesia).

According to results, the most changes in the dependent variable (anesthesia) were related to dental anxiety (moderate anxiety), in a way that changes dental anxiety from moderate to very severe increased the risk of difficult or failed anesthesia by 30.90 times. Moreover, regarding the literacy level, the change of level of education from elementary education to university increased the chance of successful anesthesia by 6.99 times.

\section{Discussion}

According to the results of the present study, $60.5 \%$ of the participants had significant dental anxiety. In this regard, our findings are in line with the results obtained by Dou et al. They resulted that the majority of participants (83.1\%) had dental anxiety ${ }^{30}$. One of the most important factors associated with dental anxiety is the experience of pain in previous visits to the dentist. According to the results of the present study, there was a significant difference among the three groups of successful, difficult, and failed anesthesia in terms of the level of dental anxiety. In this regard, the anxiety level 
was lower in the group of successful anesthesia, compared to the other two groups. Besides, the anxiety level was recognized as one of the most important predictors of dental anesthesia level.

Pain is as much a cognitive and emotional construct as it is a physiological experience $^{31}$. Thus, emotional states, such as anxiety and fear, can affect the severity of pain ${ }^{32}$.

Some studies have demonstrated that patients with a high anxiety level experience difficult anesthesia and more pain during different dental treatments ${ }^{23,33,34}$. Dental patients usually expect more pain than their previous experiences, and perception of pain is an essential factor in this regard. According to the literature, people with a high anxiety score tend to exaggerate their level of pain and fear ${ }^{23,35}$. This exaggeration leads to recording a higher score for pain, which is subjective and self-assessed by patients. However, the level of exaggeration in pain was somehow reduced in the present study due to assessing the effect of anesthesia using the Pinprick and Cavity tests. Increased dental anxiety results in a higher expectation of pain, which itself increases anxiety in patients. This vicious cycle between pain and anxiety can be partially improved by providing the patient with positive, useful information about the anesthetic process and treatment ${ }^{36}$.

Moreover, people with a high level of anxiety are often hypervigilant ${ }^{37}$. In other words, people with a high level of anxiety is always in an increased state of awareness, and they notice the slightest change in their body. Therefore, the use of distraction techniques can somehow reduce dental anxiety in these patients ${ }^{38}$. Since dental anxiety is influenced by various factors such as psychosocial factors, solving these problems can have a significant impact on reducing dental anxiety ${ }^{39}$.

Patient response is an essential factor in sensibility tests. Patients with a high level of anxiety may have a premature or false-positive response because they expect to feel an unpleasant sensation ${ }^{40}$. Individuals' cognitive and affective processing, mood, emotions, coping strategies can influence pain perception. At the same time, people with a high level of anxiety, they are more inclined to catastrophizing the pain ${ }^{41,42}$.

According to the results of the present study, there was a significant difference among the three groups of elementary education, high school, and university degrees in terms of mean dental anxiety. In this regard, subjects with primary education experienced a higher level of anxiety, compared to the other two groups, which is congruent with the results obtained by Saeed, Saatchi, et al., and Firat ${ }^{43-45}$. According to these studies, the level of dental anxiety decreased with increased literacy level. It may be due to the inability of illiterate patients to communicate with dentists. Also, people with a higher knowledge level have more information about the importance of dental and oral health.

Moreover, People with a higher level of education are also generally well-positioned, which would enable them to pay the dental treatment costs. According to the results of the present study, the mean dental anxiety was significantly higher in the age group of $\geq 59$ years, compared to the other age groups $(18-28,29-38$, and 39-48 years). In this regard, our findings are in accordance with the results obtained by Nair et al. ${ }^{46}$ and Thomson et al. ${ }^{47}$. The results of Humphris's study were inconsistent with our findings ${ }^{9}$. According to these results, the level of dental 
anxiety decreases with aging. Most subjects in the age group of $\geq 50$ years are more involved in issues related to their health and disease. In this age group, in addition to chronic disease, root canal problems, and periodontal diseases are somewhat prevalent; therefore, it can be said that these problems may cause more anxiety in this age group.

According to the results of the present study, those who had not seen a dentist for a long time experienced higher dental anxiety. This result is in line with the results obtained by Quteish Taani and Appukuttan et al. They concluded that people with a higher anxiety level more delay their visit to the dentist ${ }^{12,48}$. In other words, people who regularly visit for dental examinations have less anxiety compared to those who visit the dentist at longer periods and irregularly. Anxious people usually tend to avoid dental treatment, which is a major problem and affects their quality of life. Notably, various factors, such as lack of time and expensive dental costs, can be related to delayed visits to the dentist.

Like all studies, this study has its limitations, including that dental clinics, did not have access to an electrical pulp tester to confirm local dental anesthesia. For this purpose, they used the Pinprick test for Soft oral tissue and cavity test for hard tissue.

Although, according to the study of Lin and Chandler, the use of Electrical pulp testers is known as a subjective method which, based on stimulation of sensory nerves, and requires and relies on subjective assessments and comments from the patient $^{49}$.

Also, Agbaje and De Laat, concluded that there is a high correlation (89\% to 94\%) between quantitative and qualitative sensory testing. This result showed that qualitative somatosensory testing could be used as a screening tool in the clinical setting ${ }^{50}$.

In conclusion, although a high level of anxiety is an indication of sedation in the patients, proper interventions, such as informing patients about anesthesia, dental treatment procedures, regular and periodic visits to the dentist, as well as using psychotherapeutic techniques to reduce dental anxiety before anesthesia, could play an essential role in the success of anesthesia.

\section{Acknowledgments}

Authors would like to thank Yasuj University of Medical Sciences, Research and Technology deputy for their financial support of this study.

\section{Disclosure of interest}

The authors report no conflicts of interest.

\section{Ethics approval and consent to participate}

The research proposal approved in research ethics committee of Yasuj University of Medical Sciences and in accordance with the ethical standards of the 1964 Helsinki declaration. The ethical registration code is IR.YUMS.REC.1395.211 


\section{References}

1. Corah NL, Gale EN, Illig SJ. Assessment of a dental anxiety scale. J Am Dent Assoc. 1978 Nov;97(5):816-9. doi: 10.14219/jada.archive.1978.0394.

2. Newton JT, Buck DJ. Anxiety and pain measures in dentistry: a guide to their quality and application. J Am Dent Assoc. 2000 Oct;131(10):1449-57. doi: 10.14219/jada.archive.2000.0056.

3. Locker D, Shapiro D, Liddell A. Overlap between dental anxiety and blood-injury fears: psychological characteristics and response to dental treatment. Behav Res Ther. 1997 Jul;35(7):583-90. doi: 10.1016/s0005-7967(97)00016-8.

4. Benjamins C, Schuurs AH, And TK, Hoogstraten J. Self-reported and physiologically measured dental anxiety, coping styles and personality traits. Anxiety Stress Coping. 1996;9(2):151-62. doi: 0.1080/10615809608249398.

5. Öst L-G, Hugdahl K. Acquisition of blood and dental phobia and anxiety response patterns in clinical patients. Behav Res Ther. 1985;23(1):27-34. doi: 10.1016/0005-7967(85)90139-1.

6. Oosterink FM, De Jongh A, Aartman IH. What are people afraid of during dental treatment? Anxiety-provoking capacity of 67 stimuli characteristic of the dental setting. Eur J Oral Sci. 2008 Feb;116(1):44-51. doi: 10.1111/j.1600-0722.2007.00500.x.

7. Walsh LJ. Anxiety prevention: implementing the $4 \mathrm{~S}$ principle in conservative dentistry. Auxilliary. 2007; 17(5):24-6.

8. Hmud R, Walsh LJ. Dental anxiety: causes, complications and management approaches. J Minimum Interv Dent. 2009;2(1):67-78.

9. Humphris GM, Dyer TA, Robinson PG. The modified dental anxiety scale: UK general public population norms in 2008 with further psychometrics and effects of age. BMC Oral Health. 2009 Aug;9:20. doi: 10.1186/1472-6831-9-20.

10. Sohn W, Ismail Al. Regular dental visits and dental anxiety in an adult dentate population. J Am Dent Assoc. 2005 Jan;136(1):58-66; quiz 90-1. doi: 10.14219/jada.archive.2005.0027.

11. Kşucu ÖÖ, Akyuz S. Children's preferences concerning the physical appearance of dental injectors. J Dent Child (Chic). 2006;73(2):116-21.

12. Quteish Taani D. Dental anxiety and regularity of dental attendance in younger adults. J Oral Rehabil. 2002 Jun;29(6):604-8. doi: 10.1046/j.1365-2842.2002.00905.x.

13. Polat Ö. Pain and discomfort after orthodontic appointments. Seminars in Orthod. 2007;13(4):292300. doi: 10.1053/j.sodo.2007.08.010.

14. Santos LL. [Clinical assessment of pain levels related to anxiety, catastrophization and tooth sensitivity prior to orthodontic treatment] [dissertação]. Londrina: Northern University of Paraná; 2016. Portuguese.

15. Sullivan M, Martel M, Tripp D, Savard A, Crombez G. The relation between catastrophizing and the communication of pain experience. Pain. 2006 Jun;122(3):282-8. doi: 10.1016/j.pain.2006.02.001.

16. Martin MY, Bradley LA, Alexander RW, Alarcón GS, Triana-Alexander M, Aaron LA, et al. Coping strategies predict disability in patients with primary fibromyalgia. Pain. 1996 Nov;68(1):45-53. doi: 10.1016/s0304-3959(96)03179-x.

17. Jacobsen PB, Butler RW. Relation of cognitive coping and catastrophizing to acute pain and analgesic use following breast cancer surgery. J Behav Med. 1996 Feb;19(1):17-29. doi: 10.1007/BF01858172

18. Van Wijk AJ, Hoogstraten J. The fear of dental pain questionnaire: construction and validity. Eur $L$ Oral Sci. 2003 Feb;111(1):12-8. doi: 10.1034/j.1600-0722.2003.00005.x.

19. Armfield JM, Ketting M. Predictors of dental avoidance among Australian adults with different levels of dental anxiety. Health Psychol. 2015 Sep;34(9):929-40. doi: 10.1037/hea0000186. 
20. Locker D. Psychosocial consequences of dental fear and anxiety. Community Dent Oral Epidemiol. 2003 Apr;31(2):144-51. doi: 10.1034/j.1600-0528.2003.00028.x.

21. Canakci V, Canakci CF. Pain levels in patients during periodontal probing and mechanical non-surgical therapy. Clin Investig. 2007 Dec;11(4):377-83. doi: 10.1007/s00784-007-0126-z.

22. Singh P. An emphasis on the wide usage and important role of local anesthesia in dentistry: a strategic review. Dent Res J (Isfahan). 2012 Mar;9(2):127-32. doi: 10.4103/1735-3327.95224.

23. Van Wijk A, Hoogstraten J. Experience with dental pain and fear of dental pain. J Dent Res. 2005 Oct;84(10):947-50. doi: 10.1177/154405910508401014.

24. Carter LE, McNeil DW, Vowles KE, Sorrell JT, Turk CL, Ries BJ, et al. Effects of emotion on pain reports, tolerance and physiology. Pain Res Manag. 2002;7(1):21-30. doi: 10.1155/2002/426193.

25. Corah NL, O'Shea RM, Bissell GD, Thines TJ, Mendola P. The dentist-patient relationship: perceived dentist behaviors that reduce patient anxiety and increase satisfaction. J Am Dent Assoc. 1988 Jan;116(1):73-6. doi: 10.14219/jada.archive.1988.0162.

26. Cohen S, Fiske J, Newton J. The impact of dental anxiety on daily living. Br Dent J. 2000 Oct;189(7):385-90. doi: 10.1038/sj.bdj.4800777.

27. Haumschild MS, Haumschild RJ. The importance of oral health in long-term care. J Am Med Dir Assoc. 2009 Nov;10(9):667-71. doi: 10.1016/j.jamda.2009.01.002.

28. Boczko F, McKeon S, Sturkie D. Long-term care and oral health knowledge. J Am Med Dir Assoc. 2009 Mar;10(3):204-6. doi: 10.1016/j.jamda.2008.08.007.

29. Humphris GM, Morrison T, Lindsay S. The Modified Dental Anxiety Scale: validation and United Kingdom norms. Community Dent Health. 1995 Sep;12(3):143-50.

30. Dou L, Vanschaayk MM, Zhang Y, Fu X, Ji P, Yang D. The prevalence of dental anxiety and its association with pain and other variables among adult patients with irreversible pulpitis. BMC Oral Health. 2018 Jun;18(1):101. doi: 10.1186/s12903-018-0563-x.

31. Maggirias J, Locker D. Psychological factors and perceptions of pain associated with dental treatment. Community Dent Oral Epidemiol. 2002 Apr;30(2):151-9. doi: 10.1034/j.1600-0528.2002.300209.x.

32. Rhudy JL, Meagher MW. Fear and anxiety: divergent effects on human pain thresholds. Pain. 2000 Jan;84(1):65-75. doi: 10.1016/s0304-3959(99)00183-9.

33. Liau FL, Kok S-H, Lee J-J, Kuo R-C, Hwang C-R, Yang P-J, et al. Cardiovascular influence of dental anxiety during local anesthesia for tooth extraction. Oral Sur Oral Med Oral Pathol Oral Radiol Endod. 2008 Jan;105(1):16-26. doi: 10.1016/j.tripleo.2007.03.015.

34. Sanikop S, Agrawal P, Patil S. Relationship between dental anxiety and pain perception during scaling. J Oral Sci. 2011 Sep;53(3):341-8. doi: 10.2334/josnusd.53.341.

35. Guzeldemir E, Toygar HU, Cilasun U. Pain perception and anxiety during scaling in periodontally healthy subjects. J Periodontol. 2008 Dec;79(12):2247-55. doi: 10.1902/jop.2008.080152.

36. Canakçi CF, Canakçi V. Pain experienced by patients undergoing different periodontal therapies. J am Dent Assoc. 2007 Dec;138(12):1563-73. doi: 10.14219/jada.archive.2007.0105.

37. Chow JC, Cioffi I. Effects of trait anxiety, somatosensory amplification, and facial pain on self-reported oral behaviors. ClinOral Investig. 2019 Apr;23(4):1653-661. doi: 10.1007/s00784-018-2600-1.

38. Ghadimi S, Estaki Z, Rahbar P, Shamshiri A. Effect of visual distraction on children's anxiety during dental treatment: a crossover randomized clinical trial. Eur Arch Paediatr Dent. 2018 Aug;19(4):23944. doi: 10.1007/s40368-018-0352-x.

39. Tellez M, Kinner DG, Heimberg RG, Lim S, Ismail Al. Prevalence and correlates of dental anxiety in patients seeking dental care. Community Dent Oral Epidemiol. 2015 Apr;43(2):135-42. doi: 10.1111/cdoe.12132. 
40. Cooley RL, Robison SF. Variables associated with electric pulp testing. Oral Surg Oral Med Oral Pathol. 1980 Jul;50(1):66-73. doi: 10.1016/0030-4220(80)90334-5.

41. Kahrilas PJ, Keefer L, Pandolfino JE. Patients with refractory reflux symptoms: What do they have and how should they be managed? Neurogastroenterol Motil. 2015 Sep;27(9):1195-201. doi: $10.1111 / \mathrm{nmo} .12644$

42. Riehl ME, Keefer L. Hypnotherapy for esophageal disorders. Am J Clin Hypn. 2015 Jul;58(1):22-33. doi: 10.1080/00029157.2015.1025355.

43. Saeed NA, Hussein HM, Mahmood AA. Prevalence of dental anxiety in relation to socio-demographic factors using two psychometric scales in Baghdad. Mustansiria Dent J. 2017;14(1):38-50.

44. Saatchi M, Abtahi M, Mohammadi G, Mirdamadi M, Binandeh ES. The prevalence of dental anxiety and fear in patients referred to Isfahan Dental School, Iran. Dent Res J (Isfahan). 2015;12(3):248.

45. Firat D, Tunc E, Sar V. Dental anxiety among adults in Turkey. J Contemp Dent Pract. 2006 Jul;7(3):75-82.

46. Nair MA, Shankarapillai R, Chouhan V. The dental anxiety levels associated with surgical extraction of tooth. Int J Dent Clin. 2009;1(1):20-3.

47. Thomson WM, Locker D, Poulton R. Incidence of dental anxiety in young adults in relation to dental treatment experience. Community Dent Oral Epidemiol. 2000 Aug;28(4):289-94. doi: 10.1034/j.16000528.2000.280407.x

48. Appukuttan D, Subramanian S, Tadepalli A, Damodaran LK. Dental anxiety among adults: an epidemiological study in South India. N Am J Med Sci. 2015 Jan;7(1):13-8. doi: 10.4103/1947-2714.150082.

49. Lin J, Chandler N. Electric pulp testing: a review. Int Endod J. 2008 May;41(5):365-74. doi: 10.1111/j.1365-2591.2008.01375.x.

50. Agbaje J, De Laat A, Constantinus P, Svensson P, Baad-Hansen L. Agreement between quantitative and qualitative sensory testing of changes in oro-facial somatosensory sensitivity. J Oral Rehabil. 2017 Jan;44(1):30-42. doi: 10.1111/joor.12455. 